\title{
RELIGIOSIDADE CABOCLA NA ARTE CERAMISTA DE ICOARACI/PA
}

\author{
Religiosity Cabocla in the ceramic art of Icoaraci / PA
}

FERREIRA, Rosiane Barbosa ${ }^{1}$ UEPA - Pará/ Brasil

\begin{abstract}
RESUMO: Este artigo abordará a emergência do estudo do fenômeno religioso, por meio do imaginário dos povos do norte, está bem associado na produção ceramista de Icoaraci/PA pautado da reprodução artística das crenças Amazônicas nos objetos produzidos pela comunidade de oleiros, se dando pela criação do artista, em que este desenvolve uma primazia pelos motivos religiosos dos povos pré-cabralino existentes na região amazônica, estando os oleiros de Paracuri como agentes difusores das encantarias e o movimento do ser humano de antigas civilizações com a natureza por meio de suas peças artesanais. Através da pesquisa de campo metodologicamente entrevistando os oleiros do bairro e por meio das analises das peças cerâmicas produzidas na localidade se permitiu identificar a presença da difusão da perspectiva religiosa dos povos nativos da região como afirmação cultural na prática do oleiro icoaraciense.
\end{abstract}

Palavras-chave: Cerâmica. Religiosidade. Oleiro. Icoaraci.

\begin{abstract}
This article will deal with the emergence of the study of the religious phenomenon, through the imagery of the northern peoples, is well associated in the ceramic production of Icoaraci / PA based on the artistic reproduction of the Amazon beliefs in the objects produced by the potter community. creation of the artist, in which the latter develops a primacy for the religious motives of the pre-Cabral people existing in the Amazon region, with the potters of Paracuri as agents of the enchantments and the movement of the primitive human being with nature through his. Through the field research methodologically interviewing the potters of the neighborhood and through the analysis of the ceramic pieces produced in the locality allowed to identify the presence of the diffusion of the religious perspective of the native peoples of the region as a cultural affirmation in the practice of the icoaraciense potter.
\end{abstract}

Keywords: Ceramics. Religiosity. Potter. Icoaraci.

\footnotetext{
1 Professora Mestra e Graduada em Ciências da Religião; Especialização em Gestão Escolar pela Universidade Estadual do Pará (UEPA), Especializada no Atendimento Educacional Especializado pela Universidade de Santa Maria ( UFSM) e Licenciada Plena em Pedagogia pela Universidade Vale do Acaraú ( UVA), Atua na Secretaria Estadual de Educação como Especialista na Área da Gestão Escolar e Professora de Ensino Religioso pela Secretaria de Educação do Município de Belém, ( SEMEC). E-mail: rosa.bferreira@hotmail.com
}

REVISTA RELEGENS THRÉSKEIA - 2018 - UFPR - UEPA 


\section{Introdução}

Os conceitos etimológicos na história das crenças religiosas antigas da África, Europa e América convergem para o sentido de algo que transborda o corriqueiro em que as pessoas que se investem de autoridade, nas crenças, nos ritos e mitos. A trajetória do termo religião nos vocabulários latinos é atribuída significados correntes; etimologicamente pode-se afirmar que a palavra religião se mostra como algo estranho ao cotidiano dos templos, mesmo sendo ela, considerada universal, aparenta ser uma atividade de estranha utilidade como a palavra religio, que apresenta vários sentidos como: escrúpulo, consciência, exatidão, lealdade e outros fins que deixam o termo sem uma definição para os religiosos.

Partindo do entendimento, de que todas as culturas, todos os povos tiveram e tem uma expressão religiosa, deve então as religiões respeitarem suas riquezas e multiplicidades. Parte-se, do preceito que o religioso deva descobrir os passos ao respeito mútuo, as diversas formas e maneiras de se ler e se entender o termo religião. Na crítica da filosofia à religião, pode ser considerada como sendo a transição da construção do pensamento de Marx (2011), da juventude para a maturidade, um divisor nas obras Marxianas.

Da postura frente à alienação religiosa, (FERNANDO,1999, p.5), refere-se a religiosidade do caboclo na Amazônia, e afirma que a religião "não é patrimônio de ninguém, é condição de ser humano. Fala-se do homo religiosus que identificaria essa abertura ao transcendente, ao divino, ao sagrado". Mircea Eliade (faltou a pagina1992) comunga do mesmo pensamento e diz que, "A diretriz de que o homem é por natureza religioso, o que possibilita sua afirmação ao transcendente, não faz mais do que manifestar o caráter incrivelmente reflexivo de sua compreensão do mesmo, como uma busca dos fins últimos e sua experiência com o Sagrado".

Tratando-se de história das religiões, (ELIADE,1992), apresenta como tema fundamental o de fazer uma análise da definição do fenômeno religioso que, apresenta como características em comum, a separação entre o sagrado e o profano. Apresentando as dificuldades teóricas e práticas encontradas na pesquisa já que, principalmente no que se referem ao sagrado, os fatos religiosos não são tão simples de serem analisados. Para tal análise, o autor faz uma comparação entre o homem primitivo e o moderno em suas formas diferenciadas de vivenciar o sagrado, ou da incapacidade em que o homem 
moderno apresenta, de viver a vida como um sacramento. A configuração do Sagrado está acima de qualquer significado formado ao termo religião, e o ponto de partida seria o de compreender a relação de fé e crença, instaurada pelo termo religião entre o divino e o humano, com o sentido de purificar e conceder a relação entre a criação e o criador, em que "as formas de manifestações religiosa gera a expectativa de que a religiosidade adquira cunho especifico, conforme a personalidade ou o tipo da pessoa" (FRAAS, 1997, p.100).

Nesta perspectiva, seria a religião como reeleger (trânsito direto) onde o ser humano tem pra si o poder decisório de escolher e opinar pelo seu caminho em busca ao sagrado, e ao transcendente em busca do espaço sagrado e a sacralização do mundo. Para isso, Mircea Eliade, 1992, cita em seu trabalho, variados textos de outros autores, historiadores da religião, para mostrar as variedades da experiência religiosa do espaço. Textos estes, de diferentes culturas e épocas, dando ênfase em seus elementos de unidade. Porém na Amazônia, o modo de viver do caboclo e as diferenças entre o ser humano não religioso e o religioso, no âmbito do espaço sagrado, compreendendo as diferenças de estrutura que os separam. Mircea Eliade finaliza seu discurso, falando que somente a experiência do ser humano neste tempo sagrado "criado" por si próprio, é que possibilitará ao religioso vivenciar o mundo como era no princípio. Indissociável a vivência com o sagrado.

Acerca de uma noção transversal, entre a relação do fenômeno religioso com o aspecto social, pela grande relevância da interpretação, que atualmente pode-se fazer diante das mudanças, que perpassaram o termo religião, e suas complicações e problemas enfrentados durante todos os séculos. Ainda hoje, traçar um conceito para religião, pode se dizer como algo tendencioso, porém já aceitável, não importando a divindade, mas o respeito a ela. "Toda religião só pode ser lida na história, lugar dos fenômenos, conceitos, e por isso a formulação de um conceitual, deve conter ao mesmo tempo o princípio normativo e a necessidade da sua gradual realização". (TROELTSCH \&PRANDI, 2012, p. 263).

As diversas definições que sofre o termo religião na modernidade entre os séculos XIX e XX abrindo espaço para a antropologia e para sociologia, onde a primeira estudará essencialmente a função da religião na sociedade etnológica, e a segunda privilegiará a sociedade, tomando intensidade a respeito das discussões, já na última 
década do século XIX. Neste momento, o passo a ser traçado, perpassa pela concepção de religião bipolares a que se refere (Fernando, 2007, P.5), substantivas (ou essencialista) funcional ou exclusiva/inclusiva, predominante de conotação filosófica e teológica, trazendo à tona as descobertas de culturas selvagens, cujo primitivismo induziu os etnólogos a considerar as suas religiões como exemplares.

Os conceitos de bipolaridade às religiões de cunho universal advêm do espanto em teólogos poderem perceber que em diferentes sociedades existem crenças e credos, como é o caso vivenciado por (TAYLOR, 1996), quando ficou de frente com o animismo (crença em seres sobrenaturais), a forma mais simples de religião. A definição deste conceito por meio dos símbolos é percebida por (GEERTZ, 1989, p.67), diante de "qualquer objeto, ato, acontecimento, qualidade ou relação que serve como vínculo a uma concepção, a concepção é o ‘significado’ do símbolo”.

\section{Representações religiosas da amazônica}

Fernando Adelson, em seus escritos pontua que "O homem que vive na Amazônia brasileira tem como principal prática religiosa o catolicismo. Apesar de ser eminentemente católico, acredita em superstições, crendices que fazem parte do seu cotidiano" (FERNANDO, 2007, p. 5). Por ser a região amazônica, um arcabouço de inferência populacional, dada pelo processo de colonização, "é uma terra onde existe uma espécie de amalgamação religiosa, onde a cosmovisão do mestiço e do caboclo amazônico, foram assim convertendo-se numa intrincada amálgama de ideologia nativa e europeia" (FERNANDO,2007, p.5).

O contexto cultural amazônico, tem em seu imaginário popular, enorme representatividade regionalizada pela presença do mito, aquela que é considerada uma das primeiras manifestações culturais, metafóricas e alegóricas na maneira de expressar, possivelmente em formas antropomorfas e zoomorfas, desde os primeiros artefatos a contemporaneidade, presentes nos objetos em cerâmica. Também foram encontradas nos artefatos pertencentes ao museu de artes do Pará, objetos que possivelmente configure da existência de crenças religiosas que se propõe na pesquisa ,pelo imaginário e pelo ensaio, por sinal ( Eliade,1992 ), atribui aos aspectos dos mitos, estarem presentes em todas as culturas, e apresentam ao decorrer do tempo, vários significados que foram atribuídos a essa palavra dentro do âmbito histórico-social. Para os "modernos" o mito nada mais é que uma fábula, porém, para as sociedades 
primitivas ele é visto como uma espécie de fonte histórica, que leva a explicar os mais variados fenômenos naturais e humanos, e a criação do meio humano-natural.

Assim, como o conhecimento científico, também os saberes populares em sua materialidade (modos de constituição, expressão, conservação e difusão) exigem cada vez mais uma abordagem interdisciplinar e transcultural para que se possa vir a compreender a religião como um processo relacional desenvolvido entre o homem e os poderes por ele considerados sobre humanos; há nas crenças católicas uma mistura entre as crenças de poderes sobrenaturais, e as práticas de mágicas de origem nativa na qual, muitas vezes se estabelece uma dependência ou uma relação de dependência, que pelo olhar da semiótica "constrói relações simbólicas, entre o que conhece e o que guarda na arca da memória, e o que alimenta a sua experiência"(LOUREIRO, 2005;p.14), se expressa por meio de símbolos, emoções como confiança e até medo do castigo, advindo dos conceitos éticos e morais, que desencadeiam, com ações de culto ou atividades pré-estabelecidas em seus espaços espirituais. A religião mostra a expressão da consciência humana, registra sua relação com o sagrado, demonstrando a sua convicção no transcendente. Já a semiótica, "considera no homem a tendência de produzir uma concepção simbolizadora da experiência vivida” (LOUREIRO, 2005, p. $14)$.

A mudança de paradigmas provocadas pelas novas relações entre símbolos, imagens e expressões de crenças religiosas na região norte, nos provoca ao conhecimento do irreal, do imaginário, capaz de explorar o respeito a diversidade religiosa, com valores importantes ao exercício de crença, construída, pensada e lida. A partir do respeito histórico cultural, da universalidade religiosa, pode-se tentar conceituá-la, dentro de um contexto macro de ideologias, onde a obediência, pelo sagrado ou, o que você acredita que lhe proporcione a busca ao transcendente, deixa de se armar historicamente a tradicionais religiões existentes, adicionando espaço aos desvios de bipolaridades que elas representam para a sociedade. Dessa forma, o termo religião não possui e provavelmente não possuirá uma única definição em se tratando de estudos.

O próprio termo religião originou-se da palavra latim, cujo o sentido primeiro indicava um conjunto de regras, observâncias, advertências e interdições, sem fazer reverencias às divindades, rituais, mitos ou quaisquer outros tipos de manifestações que contemporaneamente, entendemos como religiosa. Assim, o conceito de religião foi construído histórica e culturalmente no Ocidente 
adquirindo um sentido ligado a tradição cristã. O vocabulário, "religião", nascido como produto histórico de nossa cultura ocidental e sujeito a alterações ao longo do tempo não possui um significado original ou absoluto que poderíamos reencontrar. Ao contrário, somos nós com finalidades científicas que conferimos sentido ao conceito. (SILVA,2004, p.9).

Neste caso, não se pode desprezar os conceitos epistemológicos que advém a palavra religião, esta enquadra-se o resultado da experiência pessoal e religiosa como algo positivo, que vê não apenas um conceito, mas, a vivência de cada membro em seu conceito de religião, diferente das definiçõos dadas por vários teóricos e cientistas da religião. Haja vista que, a religião é considerada como um sistema coerente de crenças e práticas enraizadas na cultura de um povo, em que não deve causar surpresa o fato de que os símbolos ou sistemas de símbolos que induzem as disposições que estabelecemos como religiosas, e aqueles que colocam essas disposições num arcabouço cósmico são na verdade, os mesmos símbolos (GEERTZ, 1989, P. 72).

No que se refere a concepção de semiótica, segundo (LOUREIRO, 2005,p.14),“o homem vê as coisas do mundo e a remolda por sua faculdade simbolizadora", desta necessidade, o ser humano ou o grupo social a que ele pertença, passa a ter sua própria forma de viver em comunidade com sua identidade posta de acordo com seu cotidiano. Novo olhar ao campo religioso a partir da cultura visual que nesta pesquisa, vislumbra, crenças em seres inanimados, por meio da arte, que possivelmente, dependendo do uso que será dado ao objeto, faz-se presente nos adereços e utensílios, que com os desenhos nos artesanatos indígenas tornam-se representações ritualísticas utilizados em seus cerimoniais em que:

A combinação das linguagens que integram a cerimônia pública acaba produzindo diferentes espetáculos: visual, estético, musical, coreografo, etc. A exposição de formas, cores, sons, emblemas, transe, música, ruídos, danças, e outros componentes da cena religiosa, que constituem a espetáculos, que proporcionam prazer e emoção aqueles que os assistem. Durante a realização das festas verifica-se uma profusão de ações imagens e comportamentos cujo significado não pode ser buscado exclusivamente na esfera religiosa, mas na relação que esta mantém com a arte, com a estética e com o contexto onde ela se realiza (SANTOS, 2005, p.14).

\section{Arte como expressão religiosa}

Pensar a arte como um reflexo do ser humano, muitas vezes, representa a sua condição social e essência de ser pensante. Apresenta-se por meio de diversas formas como: plástica, música, escultura, cinema, teatro, dança, arquitetura, e existem várias expressões que servem para descrever diferentes manifestações de arte, por exemplo: 
artes plásticas, artes cênicas, artes gráficas, artes visuais, entre outras.

A história da arte consiste em uma ciência que estuda os movimentos artísticos, as modificações na valorização estética, as obras de arte e os artistas. Esta análise é feita de acordo com a vertente social, política e religiosa da época que é estudada. Várias outras ciências servem de auxílio para a história da arte, como: a numismática, paleografia, história, arqueologia, entre outros. A arte está presente em todas as sociedades humanas. Essas manifestações podem ser muito individuais, mas dificilmente conseguiriam se isolar do seu contexto cultural e social. Loureiro (2007) compreende a história da arte como um imenso painel de conversões semióticas, isto é, da promoção da matéria e procedimentos não artísticos em arte. Mencionar arte e religião em que ambas parecem "senhoras idosas", caminhando juntas na estrada da humanidade, pois essa união parece estabelecer um paralelo da ligação homem e natureza. O homem como suas convicções, fé, crença e temor. A natureza, seus fenômenos, criaturas, magia e elementos. Sem muito entender dos fenômenos, o homem emprega a divindade e se utiliza dos materiais para reproduzir sua arte, que possivelmente estará ligada às práticas e crenças ao fenômeno religioso.

$\mathrm{O}$ encontro com as diversas linguagens que acontecem na arte propicia a aproximação do ser humano com o sagrado. Sua criação artística passa a desenvolver características do transcendente, e a despertar curiosidade entre os saberes antigos repassada nos cerimoniais. A presença da religiosidade nas criações artísticas, onde está relacionada, a partir da experiência do fenômeno religioso que ele detém, dialogando com a semiótica que "possibilita esse estado de pensamento simbólico, veículo de recepção da realidade através de significações que são decorrentes dos objetos e suas transformações em formas compreensivas do pensamento humano"( LOUREIRO,2005,p.15), pensada pela importância da visão do artista, retratada pela memória, sustentada por Gilberto Durand 1984 nos escritos de Loureiro, (2005,p.15) “em que não há mudança material sem que haja uma correlação de mudanças simbólicas". Passando assim, por uma remoldagem na significação dos símbolos ou de multiplicação dos gestos de simbolização" (LOUREIRO,2007, p.12). Ao mesmo tempo em que o autor cita Karl Max, "revelando o ato da consciência não definir a realidade e sim que a realidade possa definir a consciência", imbricado na visão Johan Hizinga por definir limites espaciais e temporais em que a realidade entra em foco como fonte 
estimulante ao processo de mudança simbólica", compreendida e integrada em um sistema comunicacional" (LOUREIRO, 2007, p. 13).

Se buscarmos pela historicidade do universo das crenças religiosas ocidentais e orientais, veremos que a artes sempre esteve presente, seja como peças e utensílios que, de algum modo, se tornaram elementos representativos na religião. Podemos exemplificar neste texto a sagrada família em que faz uma formulação da moral materialista, nos quais apresentam uma concepção de natureza humana, tendo como princípios o amor próprio, sendo adequado à expressão social.

Do ponto de vista histórico, a arte e a religião teve início com a chegada dos colonizadores às terras indígenas. Por trazerem sua influência cultural por meio da arte e da catequização dos índios, percebe-se que a arte então passa a ser utilizada como forma de doutrinação, em especial na catequese dos indígenas e africanos de maneira hierárquica. Vista, como uma forma de dominação cultural, trazendo para esses grupos, outro tipo de religiosidade e nova visão de mundo, que se baseava no poder de convencimento, por meio das artes.

Após cem anos de desenvolvimento na Europa, entre os séculos XVIII e XIX, com a associação das religiosas leigas, como confrarias e irmandades, que começam a patrocinar as produções artísticas, que se misturando a outros estilos como, por exemplo: os franceses, espanhóis, italianos, modificando-se ainda mais pelo contato com o povo miscigenado entre os europeus, negros e índios. Dada à mistura das etnias, havia juntado a mistura de ideias que começou a ser a preocupação da igreja e do estado, pois traziam consigo a diversidade de ideias, crenças religiosas, sendo proibida pelo catolicismo. (GOMES, 2002, P. 23).

No Brasil ela chega por volta de 1759 , tendo como percursores os primeiros padres jesuítas com o objetivo de catequizar e evangelizar os indígenas, que culminaria com a expulsão dos mesmos, de suas devidas colônias. A proibição era ensinada sobre textos em versos, e os conteúdos religiosos por vez, apresentados em forma de alegorias. Um exemplo está na fala de Vidal (1992) quando segundo o pensamento colonizador "os rituais e ornamentação indígenas se referem à figura do demônio".

Diante do olhar do colonizador, as manifestações de crenças indígenas, são vistas como algo de extremo repúdio, pois, causam a eles, medo, que expressa o fenômeno religioso, por meio das crenças de novos grupos. Por outro lado, podemos pensar que as manifestações religiosas de uma cultura empírica, que é criada da oralidade e costumes de um povo, estão ligadas à arte pelo uso que é feito dos objetos 
por eles criados. Em sua dissertação: A linguagem iconográfica da cerâmica marajoara, no capítulo: arte indígena e significado, Denise Schaan, (1997), levanta, por meio de estudos arqueológicos, registros étno históricos do "significado dos objetos, que para os povos da mata é totalmente natural, dentro de suas crenças e culturas".

A igreja, por outra vertente catequizadora, tenta mostrar por meio das artes visuais, a prática dessas outras religiões, como de hábitos considerados pecaminosos (como roubar), estaria relacionada ao inferno e, consequentemente, seria punida por Deus. No entanto, pouco atingia seus objetivos com a população ameríndia em que: "A religiosidade tem sua expressão nos seres místicos, a exemplo dos espíritos da floresta", segundo a ideia de (GOMES,2002,P. 52).

Esse enquadramento desfaz a ruptura do olhar do arqueólogo por meio das diversas produções artísticas dos povos existentes antes a colonização dada às tentativas de catequizar os índios e que tornavam-se frustrantes para os jesuítas neste período, pois, a dança, a música, as cores (em especial o vermelho), eram bastante usadas nos espetáculos, principalmente em cenas que apareciam o diabo. Como os índios não distinguiam essa relação de temor a uma determinada entidade instituída pelo cristianismo católico, esse povo sentia-se mais atraído do que temeroso, diferente do que ocorrerá com os demais imigrantes e descendentes, visto que, as peças eram apresentadas dentro e fora das igrejas, nas ruas, nas praças onde se julgasse necessário.

Quando nos reportamos, aos antepassados, lembramos das comunidades ameríndias que usavam de suas experiências para cultuar as obras da natureza por meio da arte em seus objetos e utensílios usados em rituais, festas, cerimoniais entre outros acontecimentos da comunidade. "Estético -religioso das encantarias- espécie de olimpos submerso nos rios da Amazônia, onde habitam os encantados, os deuses da cultura amazônica - e a atmosfera universal que impregna toda poesia" (FERNANDO,2007,p.5). A relação dada com a natureza parte de seu cotidiano e o poderia ser encontrado para simbolizar seus deuses.

Denise Schaan (1997, p.7), realça que, "ao se entender a existência da arte indígena, ela, é pensada, dentro de culturas humanas”. Significa admitir que a arte indígena contém parte inseparável do seu grafismo ( símbolo) com o sagrado, pois um simples vaso de cerâmica, torna-se um símbolo religioso quando utilizado e pintado para seus rituais, como quando utilizados para o uso da bebida ayahuasca. Estudos 
realizados por Denise Schaan referentes à arte indígena, colocam-na no contexto de diferentes manifestações humanas, sociais, estéticas. Para, (SCHAAN,1997,p.13).“Os objetos a que chamamos artísticos, têm, portanto, nas sociedades indígenas, não só significados estéticos, mas também social, étnico, religioso, moral, e simbólico", por isso, que a arte indígena abre precedentes, podendo ser estudada do ponto de vista de várias áreas do conhecimento: da filosofia, história, sociologia, antropologia, arte e religião, haja vista, o grande desconhecimento e a forma estereotipada, com que se pensam as culturas e a arte desses ancestrais.

A arte indígena vem embebida de crenças, ritos e mitos que fazem dela expressão do sagrado para seu povo. Na leitura de Vidal e Silva, os objetos que chamamos artístico têm para sociedade indígena significado social, mas também religioso, quando: "as próprias culturas indígenas não recortam, dentro de sua experiência coletiva, uma esfera separável que poderia ser qualificada de cultura material ou artística" (VIDAL e SILVA 1995, p.373). É nesse entendimento que o autor evidencia que a arte nunca deixou de ser um elemento importante na religião. Quer seja pelo seu carisma, beleza e misticismo, a arte foi o melhor e mais importante marketing que a religião já teve e tem. Também não se deixar de constatar que a religião foi e ainda é, um espaço de desenvolvimento da arte e do artesanato. Do ponto de vista da semiótica é importante suscitar a discursão da reformulação ideológica dos símbolos como elementos que tornam os objetos cerâmicos atrativos, o que constitui, classificar algumas peças que na prática do artista, foram utilizadas por diferentes sociedades indígenas, neste ou em outro período da história. Isto é, que permitissem a leitura com os conhecimentos antes elaborados por pesquisadores das áreas, antropológica, histórica, filosófica e arqueológicas de modo interdisciplinar.

\section{Conhecimento sobre os mitos amazônicos através da cerâmica de Icoaraci/PA}

O efeito da conversão semiótica, por meio do pensamento simbólico, passa a ser o veículo para que aconteça a recepção, significação, circulação e ressignificação da realidade dos objetos e "sua transformação em formas compreensivas do pensamento humano"(LOUREIRO,2007,P.15), que caracteriza-se pela capacidade humana de elaboração e reelaboração dos símbolos. Estes símbolos são facilmente encontrados nos objetos confeccionados em cerâmica em Icoaraci, distrito de Belém/PA, como esta criação artística na peça de cerâmica em objeto de uso utilitários com traços e pinturas 
marajoaras, tendo sua borda pequenos traços de agregação.

Há uma organização sociocultural por meio de seus sistemas de crenças, credos e ritos que podemos encontrar entre os oleiros da região de Icoaraci/PA, expressa em muitos de seus objetos em cerâmica, que passam a circular por vários campos religiosos. Em que os estilos e simbologias de pinturas realizadas em grutas, corpos humanos, hoje, estão reafirmados na arte ceramista; ressalta-se ainda que em uma concepção de sociedade indígena a arte confunde-se com a própria cultura, onde se buscou entender como um símbolo compartilhado pelos membros de uma sociedade criando muitas narrativas, contadas por meio do mito e expressas nos objetos cerâmicos.

Essas conexões atribuem significado especial aos desenhos grafados nas cerâmicas, pelo significado dado ao símbolo, firmando o acreditar nos pressupostos de fortes influências ameríndia, revelada na arte produzida pelos oleiros, peças, crenças e práticas religiosas de encantarias e mitos da região Amazônica, estão visivelmente expostas, registradas por meio dos deuses sol, terra, biodiversidade. "Essas crenças se referem aos curupiras, aos anhangás, a cobra grande, a matinta pereira, os botos e outros mitos e encantarias que envolvem a zona rural. Cada qual apresenta um conteúdo de "verdade", estão recheados de valores, aos olhos de quem os cultuam e os temem" (FERNANDO,2007, p.5). Dentro dessa lógica, os mitos servem, geralmente, para relatar a criação do cosmos, dos fenômenos, da morte, da sexualidade, enfim, para tudo. E essa "criação" se deu por meio de seres sobrenaturais (divindades) ou de heróis humanos, que foram marco na história daquele povo. Os heróis humanos cultuados, pelos ameríndios reproduzidos por estatuetas, urnas funerárias, para além das diferenças, há um ponto em comum, os traços de deuses e semideuses, podem nos remeter a várias leituras, olhares e o que encontramos nas falas dos oleiros como Sr. Rosemiro, (2017), em que as peças são confeccionadas de maneira estilizada. 


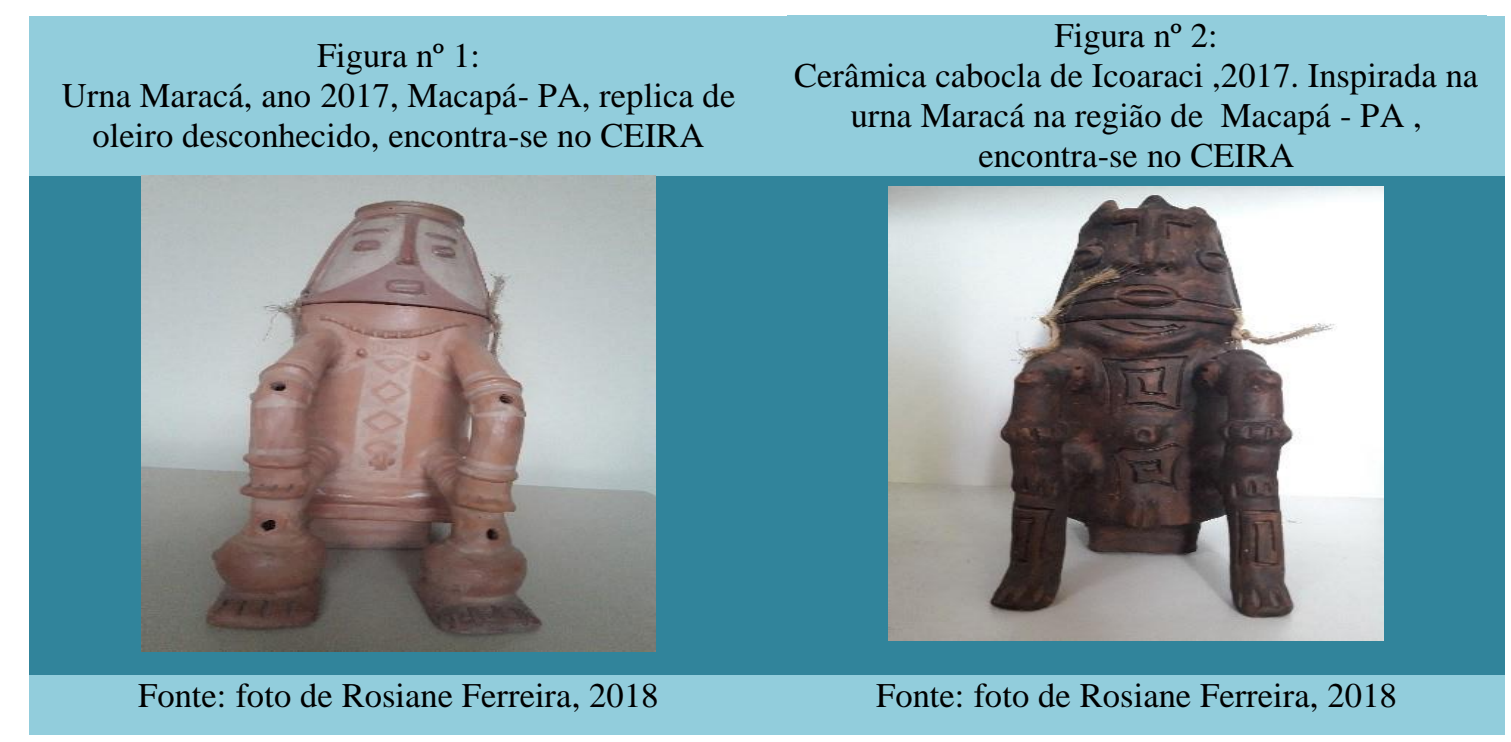

Ao analisar as figuras, adquiridas de diferentes oleiros, presenciou-se a modernidade de estilos e diferenças contidas entre uma peça e outra. A primeira figura, mesmo considerada uma réplica no meio artístico, apresenta traços, originários dos artefatos encontrados por desbravadores da época, mostrando uma imagem clara, com possíveis traços de ser um deus branco de expressão singela, com desenhos e grafias pintadas nas cores brancas. A segunda, em uma nova criação, que advém da bricolagem, ou de um nova leitura por quem a cria, contextualiza sobre a peça de cerâmica, urna Maracá de traços africanizados, de cor escura e com alto relevo e agregações estilizadas, diferenciam a cerâmica Maracá, por mesclarem traços desenhados, perfurados, com cor em uma única tonalidade, predominada pela argila escurecida. Essas observâncias nos trazem a luz da influência cabocla do oleiro, e uma divisão social de raças. Passando a ser a leitura desta pesquisadora, um objeto de cerâmica cabocla original, apoiado pela releitura que o mestre realiza e emana seu conhecimento histórico, cultural, pragmático e religioso.

Mesmo passando por ressignificação do modelo contemporâneo, figuras 01 e 02 , carregam em seu histórico vários mitos, em que estes, não são apenas histórias que levam à criações, mas também é uma forma de explicar o comportamento social humano, algo que aconteceu e que mudou de forma drástica o modo de vida dos povos no qual estes estão relacionados, ou que faça com que esses povos tomem atitudes que levem a um resultado predito nesses mitos. Podemos verificar isso na cultura dos Navajos no qual os homens e as mulheres devem sentar-se da forma que as divindades 
que representam os respectivos sexos sentaram no momento da criação (BOAS, 2014, p.77).

O fato de conhecer a origem das coisas não é somente histórico para esses povos, mas eles acreditam que conhecendo a criação eles absorvam poderes mágicos sobre as coisas. "A religiosidade tem sua expressão nos seres místicos, a exemplo dos espíritos da floresta". (GOMES, 2012, p. 52). Portanto, a função dos mitos é basicamente explicar, de forma "religiosa", a origem do mundo e do comportamento das pessoas. Muitos estão presentes nas sociedades primitivas, que ainda estão se mantendo vivas mesmo com a expansão tecnológica e a globalização, e muito disso está presente, também, na sociedade moderna global. No que implica a posição do artista dentro do quadro de criação artística, ao elaborar proposta consagrada a conceituação de arte e crenças Amazônica, (LOUREIRO, 2007, p.18), carrega em significações cristalizadas, sendo esta forma de conhecimento percebido pela linguagem de conversões semióticas, isto é, a semiologia, promove a dominância material e procedimentos não artísticos em arte.

Assim, a arte pelo viés das crenças, que envolve o ecossistema, é vista como ação do homem indígena na construção e criação do objeto, responsável por causar por meio da atividade humana, manifestações de ordem estética, e como nada está só, o artista, a partir de percepções, emoções e ideais, integra a linguagem do contexto. Estimula interesses de consciência em um ou mais espectadores, e cada obra de arte possui um significado único e diferente, pois está ligada à estética do exterior do homem ameríndio, que (LOUREIRO, 2007, p.23) enfatiza como sendo "numa imagem, numa ficção, num modo irruptivo do instante que nunca é igual a outro", considerando, em seu sistema, uma faculdade ou ato pelo qual, trabalhando uma matéria, a imagem ou o som, o ceramista cria, levando em conta os novos horizontes abertos pela beleza das peças produzidas, ao se esforçar e dar expressão ao mundo material ou imaterial, que o inspira pelos seres existentes na fauna e flora Amazônica.

Sob a influência das diferentes tribos da região Norte, sobretudo a região do Marajó, Macapá e do Tapajós, que pelas suas características, emergem uma linguagem da história natural na criação de objetos utilitários, desta forma, visto como não artístico, distanciando-se de ser a consciência da coletividade.

No entanto, expressada na obra do oleiro, a arte passa a ser objeto totalmente 
modificada de sua originalidade ancestral, sob referência em grande parte dos dados coletados por meio de escritos, descrições, comentários, opiniões, crenças de viajantes, exploradores, comerciantes e religiosos, entre outros, que possibilita uma integração. Muito embora, se saiba que pela perspectiva favorável em que se permaneça o conteúdo histórico, a que foi construído e conhecido o objeto, como exemplo, a urna funerária Maracá, que mesmo descaracterizada, pelo olhar dos arqueólogos e historiadores, passa a ser analisada por pesquisadores contemporâneos, como sociólogos, antropólogos e filósofos por uma nova vertente, em que se considera todas as esferas da formação do ser humano, que produz ou fabrica a peça. Neste sentido há um ponto de partida que se inicia com a arte rupestre, os achados de cerâmicas em comunidades indígenas, até a nova versão da arte do oleiro.

Desse modo poderia relacionar a arte ceramista à região amazônica ou elencar que ambas sempre estiveram interligadas, como pela guinada que a pesquisadora Denise Schaan (1997), traz à tona as relações dos indígenas com a natureza, e sua compreensão com a cosmologia. Suas manifestações socioculturais utilizando-se das pinturas corporais para manifestar seus princípios, expressando sua crença e sua conexão com o sagrado por meio da ornamentação. Como principal elo a pintura nos corpos, assim como os objetos por eles confeccionados e utilizados, bem como a cerâmicas que seria o objeto de estudo dessa pesquisa.

Embora nos deparemos com um duplo movimento, entre presente e passado na contemporaneidade, a particularidade que compõe e possibilita a releitura das peças como o exemplo da urna Maracá. Conservam, ou seja, mantem-se as características, mesmo com detalhes inovadores, mudança de cor, e sendo utilizada na representação do objeto em seu imaginário popular, não deixa de ser a urna da cabeça quebrada, fluentemente encontrada e comercializada, como objeto utilitário - decorativo, que era usada pelos povos primórdios no sepultamento de guerreiros e deuses. 


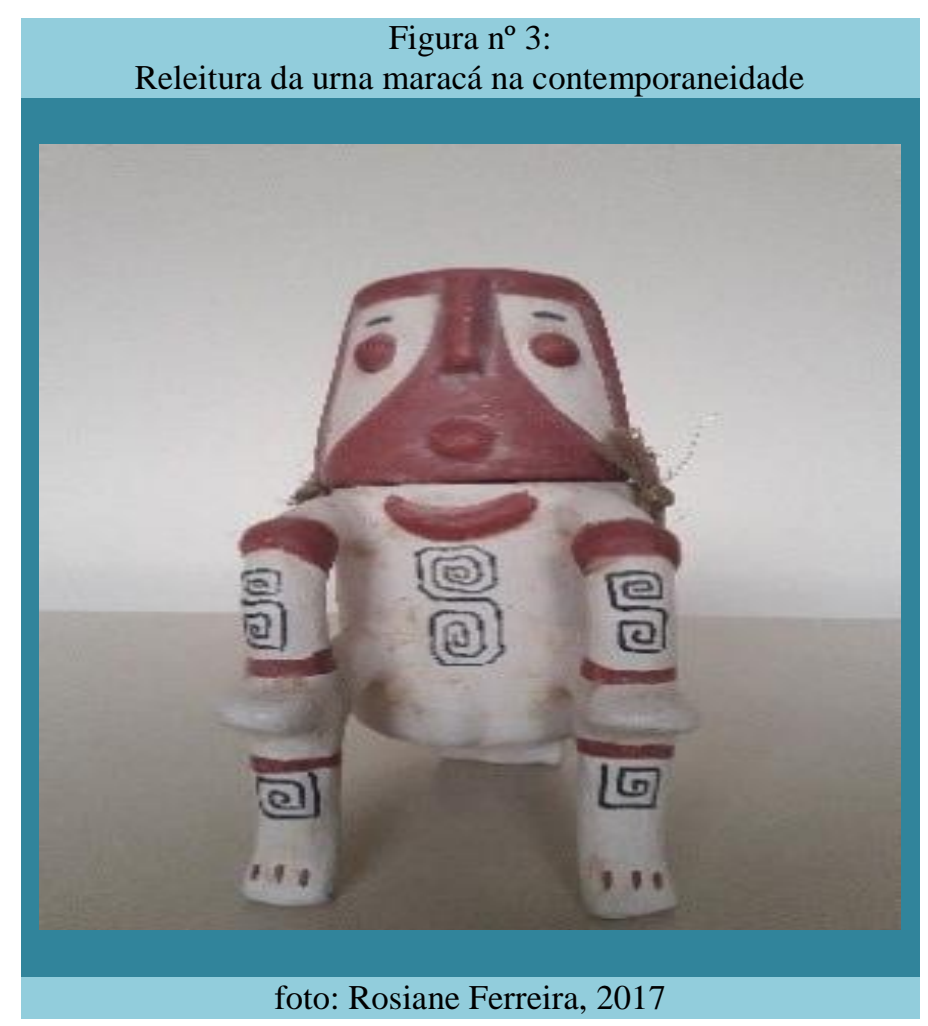

Este enfoque permite a reflexão de peças adquiridas, e o uso que dessa se faz por quem a adquire. Na semiometria, o mito se faz presente pelo acúmulo da historicidade de um povo primitivo. A cor vermelha (urucum) e preta (jenipapo), pinturas de grafismos Marajoaras. Então ao desdobrar o olhar à peça, pode-se fazer várias leituras, interpretações de acordo com a percepção holística de cada indivíduo, mas que irá remeter-se a deuses ou cacicados importantes que habitou a região Amazônica.

Para contextualizar a habilidade e as técnicas do oleiro na criação da obra, traremos para a conversa o conceito de arte, como sendo um termo que vem do latim, e significa técnica/habilidade que varia de acordo com a época, a cultura, arte rupestre, artesanato, arte da ciência, da religião e da tecnologia. Atualmente, a arte é usada como a atividade artística ou o produto da atividade artística. A arte é uma criação humana com valores estéticos, como beleza, equilíbrio, harmonia que representam um conjunto de procedimentos utilizados para realizar obras. Susanne Langer (1980) apud Loureiro (2007), entende a arte como expressão simbólica de uma cultura, considerando-a prática de criar formas perceptíveis do sentimento humano, (LOUREIRO,2007, p,18).

REVISTA RELEGENS THRÉSKEIA - 2018 - UFPR - UEPA 
Podemos dizer que a arte, a religião e a ciência andavam juntas na figura e, originalmente, a arte poderia ser entendida como o produto ou processo em que o conhecimento é usado para realizar determinadas habilidades de esculturas, pinturas, sapatos ou navios, pois "se integra na vida cotidiana, insere-se no meio ambiente e atua como vetor de transformação do espaço público (LOUREIRO, 2007; p18).

Há uma tendência atual que busca, dentro das tradições indígenas, resgatar as concepções de credo, e cultura dos povos. Preocupação esta, que se pode encontrar no processo de educação indígena contemporâneo, acervos guardados no Museu Emilio Goeldi, que redesenham leituras diferenciadas as peças que estão à venda nas olarias e podem ser mensuradas pela diversidade e multiculturismo em que o espírito do fenômeno por meio da conversão da semiótica trazida por Paes Loureiro. Diante do princípio de que existe uma evidente relação que possibilita uma combinação entre as linguagens, expressões artísticas e o sagrado, chega o momento de destacar o elo existente desperte a iminência de juntar arte cerâmica e religião em representação simbólica a cerimoniais herdados dos antepassados.

Para dar forma à sua crença, o oleiro expressa suas obras no objeto saído do irreal para o real, onde as crenças passam a ser expostas por meio das representações simbólicas, fazendo com que exista a necessidade de representar estas figuras através da arte mostra a ação do que para o artista é a representação sagrada e uma realização mística. Em que Santos afirma ser através dela que o sagrado 'deixa de ser algo invisível e inefável e passa a adquirir uma forma bela e real' (SANTOS, 2005, p. 17). Neste sentido, podemos dizer que, a arte indígena reproduzida pelos oleiros na cerâmica confunde-se com sua própria cultura concordando com (SCHAAN, 1997, p.7), quando afirma "ser a cultura como código simbólico compartilhado pelos membros de uma sociedade". Por este motivo, acredita-se que a compreensão dos significados simbólicos somente é possível dentro da própria cultura de quem os produziu, uma vez que a arte manifesta, expressa e dialoga com o cotidiano e o sobrenatural das diferentes sociedades indígenas.

Ao considerarmos as afirmações anteriores infere-se a pertinência de se procurar nos artesanatos produzidos nas regiões, outrora habitadas por esses povos a persistência da marca dos mesmos. Se existe produção artesanal ou artística, podemos pensar então que as produções contemporâneas nos trazem um legado de informações sobre estes 
povos. Do ponto de vista da semiótica é importante suscitar a discursão da reformulação ideológica dos símbolos como elementos que tornam os objetos cerâmicos atrativos, o que constitui, classificar algumas peças que na prática do artista, foram utilizadas por diferentes sociedades indígenas, neste ou em outro período da história. Isto é, que permitissem a leitura com os conhecimentos antes elaborados por pesquisadores das áreas, antropológica, histórica, filosófica e arqueológicas de modo interdisciplinar.

Muitos estudos, podem ser percebidos e praticados antes de serem conceituados, o que certamente muda toda a visão de não existência de fundamentos de crenças e mitos nos objetos cerâmicos. Uma vez que ao acompanhar os passos do desenvolvimento do oleiro, podemos agrupar os conteúdos pelos critérios de possíveis vivências que podem ser simbolizados, posteriormente agregados, mediante as organizações mentais concretas que se percebe por meio da função semiótica em que está acoplado o nível de linguagem, leitura vocabulário, representação gráfica e expressão corporal do oleiro.

Ao planejar e criar uma peça, o oleiro parte de revisão do período imediatamente anterior ao pretendido, ou mesmo de todos os períodos anteriores. Neste momento o mestre ceramista, precisará então organizar mentalmente um possível planejamento quanto ao representável visual que se sustenta por meio da função semiótica em níveis de linguagem, as diferentes fases de representação gráfica (desenhos) de realismo fortuito ou realismo intelectual apresentada por Jean Piaget no desenvolvimento infantil, em que o artista "representa os objetos que vê e também os que estão ausentes".

A restrição da inventabilidade não se deve, como talvez poderíamos supor, ao hábito de copiar desenhos antigos e a um lentidão da imaginação do artesão que acha mais fácil copiar do que inventar. Pelo contrário os artistas primitivos quase nunca copiam. (BOAS,2014, P.156).

A titulo de exemplificação se tem a consideração da peça em seu todo, uma representação e criação do que conceituamos "Cerâmica Cabocla". O objeto foi confeccionado pelo oleiro Rosemiro sob encomenda do professor Dr. Manoel Moraes em 2017, quando visitou o campo de pesquisa e foi doada ao museu do grupo de pesquisa CEIRA da Universidade Estadual do Pará. No início foi encomendado, apenas um simples pote. No dia de receber a encomenda, tivemos a notícia do oleiro Rosemiro que a peça estava com valor mercadológico mais alto do que o informado 
anteriormente, visto que, este havia agregado valores de pintura marajoara à peça criação do mestre da olaria . Foi então que sugeriu-se o conceito de criação ímpar de objeto Cerâmico Caboclo que consiste na "essência do gesto criador e a transformação configuradora do silêncio em signo"(LOUREIRO,2007,p.22).

O pote em cerâmica de uso utilitário, um objeto usado para o armazenamento de líquidos, por comunidades indígenas e não indígenas da região amazônica, passa a ter um perfil de ornamentação estilizada, com pinturas marajoara, muitas vezes encontradas nos corpos, adereços utilizados em seus rituais, passa a ser desenhado nos objetos trazendo e agregando valor material, cultural, histórico e ritualístico.

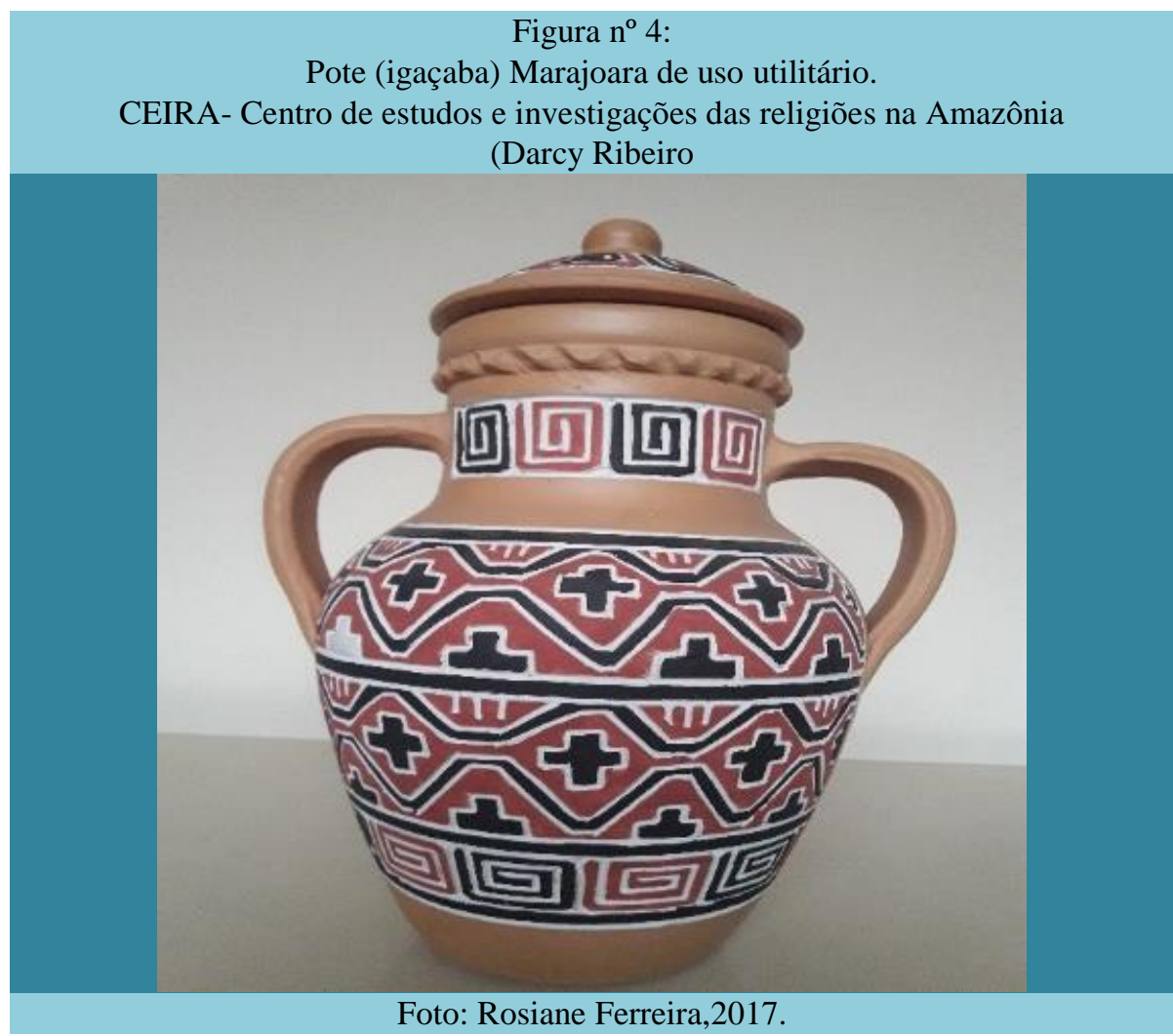

Como acontece o trânsito religioso de pessoas em diferentes espaços religiosos, os objetos que saem das olarias são utilizados em diferentes espaços. O pote marajoara, quando usados nas religiões de matriz africana é um dos objetos mais usados dentro do candomblé, e são nomeados de quartilhões, Yaba (com alça) e Aboro (sem alça), as quartinhas que são potes menores sem alças e os alguidares chamados de Oberos, recebe o nome de objetos utilitários nas tradições indígenas, em que são convidados pela difusão religiosa de um legado histórico, social, cultural de crenças e mitos que cercam desde a infância a vida do oleiro Amazônico.

REVISTA RELEgENS THRÉSKEIA - 2018 - UFPR - UEPA 
Considerando, o que diz Loureiro (2005, p. 14): “O pensamento puro do homem sobre o objeto, depende de um ato autônomo e espontâneo da consciência. Numa formação resultante das condições de intuição do pensamento puro", passamos a interpretar a religião como uma mera propriedade criada por meio do ser religioso autônomo, consciente de suas crenças e credos, capaz de reelaborar por meio das representações irreais, coexistentes no símbolo, determinadas formas de ser religioso, a partir do que ele denomina ser religião. Neste momento a criação expressa sua singularidade no objeto confeccionado, logo, estamos nos aproximando de uma nova leitura de serem os objetos não réplicas, ao contrário, são peças originadas de um arcabouço de agregações não somente antropológica ou rupestre, outro sim, recheado de diversidade religiosa, magia e crenças dos elaboradores das novas peças.

As cerâmicas caboclas ou cerâmica neobrasileira, que tem por sua característica, representar culturas diferentes que se fundiram originando um novo padrão de decoração e confecção, fabricadas na contemporaneidade e vem sendo recepcionada como reflexo do colonialismo europeu. Para continuar a viagem pelo imaginário amazônico, sob o minucioso olhar antropológico, buscou-se o pioneiro em estudar a diversidade religiosa do caboclo na Amazônia.

Segundo Maués (2005), foi Eduardo Galvão, que encontrou incentivo nas leitura intituladas" Vida religiosa do caboclo da Amazônia ( 1953) ; Santos e Visagens: um estudo da vida religioso de IT, 1955, o que para nós é fundamental a análise da conversão semiótica nas pesquisas e representações caracterizadas nas peças em cerâmica, que retratam a diversidade religiosa do caboclo que reside na Amazônia, estudada por Raymudo Heraldo Maués, entre os anos de 1975 e 1986, a despeito de algumas variações de crenças e práticas de aspectos religiosos da cultura cabocla amazônica, "representada de grande riqueza de mitos, concepções, crenças e práticas, somando a isso a diversidade religiosa indígena, suas variações linguísticas, formas comportamentais, mitos , crenças e etnias" (MAUES, 2005, P.259).

\section{Considerações finais}

Acerca das interpretações acerca da originalidade das novas peças em cerâmicas, consiste em uma releitura do artesão presenciado na maneira como se produza cerâmica em Icoaraci/PA, estando relacionado ao seu tempo, sua época e sua vivência no mundo contemporâneo. Um fato importante é que este ceramista diferencia-se dos demais, em 
termo de tradição repassada de pai para filho; Outra forma seria que esse oleiro tem consciência a respeito da origem das peças e diz: "vem da cerâmica Marajoara, Maracá e Tapajônica. São peças parecidas, não réplicas, pois agregam os desenhos para vendas, são criadas em Icoaraci” (ANISIO, 2016).

Ao ouvir as opiniões de indivíduos que criam os desenhos novos, vimos que estes se dão pela combinação, polissemia do símbolo, pela leitura que este faz e as possíveis interpretações a partir dos desenhos da arte rupestre, modernizando e adaptando de acordo com as exigências do mercado. A Arte rupestre foi inserida na cerâmica, e ao longo do tempo vem se modernizando, segundo a fala êmica em que ao ser perguntado como aprendeu o oficio de oleiro afirma: "realizei muitos estudos com arqueólogos e participei de cursos no museu Emilio Goeldi

Deste modo, a meu ver, essas variações de crenças estão intrínsecas na historicidade da árvore genealógica dos oleiros e passam a ser experimentadas e colocadas para fora, na medida em que constituem elementos presentes em suas obras artísticas, que evocam, não somente o que vem da história, da cultura de outras comunidades, sobretudo, insere a sua essência em cada objeto confeccionado.

\section{Referências}

AMORIM, L. B. de. Cerâmica marajoara: a comunicação do silêncio. Belém: Museu Paraense Emílio Goeldi, 2010

BASTOS, Solange. Na rota dos arqueólogos da Amazônia, 13 mil anos de selva cultivada. Prefeitura de Eduardo Góes Neves. Teresópolis: Família Bastos Editora, 2015

BARRETOS, C. Cerâmica e Complexidade Social na Amazônia Antiga: uma perspectiva a partir de Marajó. In PEREIRA,E;GUAPINDAIA,V.(org) Arqueologia Amazônica I.Belem, Boletim do Museu Paraense Emilio Goeldi. 2016

Boletim do Museu Paraense Emilio Goeldi. Ciências Humanas,2009- Belém:MPEG,2009,v.4n.1v.il.Semestral:1984-2002.

Interrompida:2003;2004.quadrimestral a partir do v.1,2005. CDD-21 ${ }^{\circ}$, ed.300

BARRETO, C; LIMA, H.P; BETANCOUT, J. (org) Cerâmica arqueológica na Amazônia: rumo a uma nova síntese. Belém, IPHAN: Ministério da cultura, 2016 pp 19-31.

BARRETO, C. A construção do passado pré-colonial: uma breve história da arqueologia no Brasil. Revista USP, v.44, p. 32-51, 1999-2000.

Arte e Arqueologia na Amazônia Antiga. In GRUPIONI, L.D. (Ed.)

Brésil Indien: Les arts des Amérindiens du Brésil. Paris : Hoebeke, 2005.

REVISTA RELEGENS THRÉSKEIA - 2018 - UFPR - UEPA 
CERTEAU. M. A invenção do cotidiano, Rio de Janeiro, p.39, editora vozes ( Petropolis-Universitaria,

DURAND, G. As estruturas antropológicas do imaginário. Introdução a arqueologia geral.editora Martins Fontes, 1997

DURAND, G.Les structures anthropologiques de I'imaginaire. Paris: Dunod,2016. em:www.seer.ufrgs.br/intexto/article/download/75641/43475

ELIADE, M. O sagrado e o profano: a essência das religiões. São Paulo: Martins Fontes, 2001.

ELIADE, M. Tratado de história das religiões, 1977, editora: Cosmos

FERREIRA, L. M. Território primitivo: a institucionalização da arqueologia no Brasil (1870-1917). Tese de doutorado pela Universidade Federal de Pelotas, 2007

FIGUEIREDO. A. M. Escravos e senhores nas irmandades religiosas na Amazônia do século XIX, Amazônia IPAR- Ano3-Número 5 agost/dez/de 2001

FILORAMO, G. e PRANDI, C. As ciências das religiões. São Paulo: Ed. Paulus,2017

FUNARI, P.P. Arqueologia. São Paulo: Contexto,2003

GUAPINDAIA, V. L. C. O acervo arqueológico. Belém: Museu Paraense Emílio Goeldi. 2003. Manuscrito

GEERTZ, C. 1978. A interpretação das culturas. Rio, Zahar. 1983 Local Knowledge. Further Essays in interpretative anthropology. New York, Basic Books, Inc.

GOMES, A. O. T. As relações entre filhos/as de santo no cosmo religioso umbandista: uma abordagem a partir do contexto de Viçosa/AL. Dissertação de mestrado, para ULHUT, Lisboa, 2012

GOMES, D.M.C. Cerâmica Arqueológica na Amazônia: vasilhas de coleção Tapajonica. MAE-USP. São Paulo: EDUSP; FAPESP:Imprensa oficial, 2002

GOMES, J. Arqueologia e cultura material na RDS Amanã: analise cerâmica dos sítios Cacoal, Calafate e São Miguel: relatório técnico final/CNPq.Tefé, 2012

LIMA, D. M. A construção histórica do termo caboclo: sobre estruturas e representações sociais no meio rural Amazônico. Novos cadernos NAEA vol.2, $\mathrm{n}^{\circ} 2$, dezembro ,1999

LISBOA, A. Aspectos da Subjetividade Religiosa na Arte Contemporânea. $18^{\circ}$ Encontro da Associação Nacional de Pesquisadores em Artes Plásticas Transversalidades nas Artes Visuais - 21 a 26/09/2009 - Salvador, Bahia http://anpap.org.br/anais/2009/pdf/cpa/ana_elizabeth_lisboa_nogueira_cavalcanti.pdf

LOPES, P.R. Caracterização do modo de vida dos sambaquieiros que ocuparam o litoral amazônico. Projeto de Doutoramento. Rio de Janeiro: Museu Nacional/UFRJ,2012

LOUREIRO, J. de J. P. A conversão semiótica: na arte e na cultura- Edição trilíngueBelém:EDUFPA,2007.

MAGALHÃES, M. Arqueologia na Amazônia pela perspectiva inter-relativa. In: Amazônia Antropogênica. Marcos Pereira Magalhães, Organizador. Belém: Museu Paraense Emílio Goeldi, 2016. 
MAUES.R.H. Um aspecto da diversidade cultural do caboclo amazônico: a religião, av.[on line].vol.19,n53,pp259-274. Ano, 2005

MAUES. R.H. E G.M VILLACORTA. Pajelança e encantaria amazônica. Trabalho apresentado nas VIII Jornadas sobre Alternativas religiosas na América Latina, São Paulo,22-25 set.1998

MORAES JUNIOR, M. R. O materialismo histórico revisado. Habermas após Max. Problemata- revista internacional de Filosofia, v8, p.203-2018, 2017

MUSEU PARAENSE EMÍLIO GOELDI. Arte da terra: resgate da cultura material e iconográfica do Pará. Belém: SEBRAE, 1999

NETTO.C.X.A. e SOUZA de A.J. A importância da cultura, p.120-121, 2010

PEREIRA, E. Arte Rupestre na Amazônia - Pará. Belém: Museu Paraense Emílio Goeldi; São Paulo: Unesp, 2003.

PEREIRA, E. Arte Rupestre na Amazônia - Pará. Belém: Museu Paraense Emílio Goeldi; São Paulo: Unesp, 2004.

PEREIRA, E. O Sitio Domingos - Uma Aldeia Tupi Guarani no Sudeste do Pará, Amazonia, Brasil. In: CONGRESSO DA SOCIEDADE DE ARQUEOLOGIA BRASILEIRA,15 SIMPOSIO ARQUEOLOGICO TUPI (GUARANI) NA AMAZONIA : ESTUDOS REGIONAIS 2009, Belém. Resumos...2009

Análise Preliminar das Pinturas de Monte Alegre (PA). Bol. Mus. Par. Emilío Goeldi (Belém), v.8, n.1, p.5-24, 1992.

Levantamento Arqueológico dos Sítios com arte Rupestre do Baixo Amazonas. Relatório de Pesquisa. Belém: Museu Paraense Emílio Goeldi, 1992.

Arte Rupestre na Amazônia. In: VV.AA. Arte da Terra: Resgate da Cultura Material e Iconografia do Pará. Belém: Museu Paraense Emílio Goeldi, Sebrae, 1999.

RODRIGUES, C. I. Caboclos na Amazônia: a identidade na diferença. PPG/UFPE, 2002. Parte de Tese de Doutourado: vem do bairro do Jurunas: sociabilidade e construção de identidades entre ribeirinhos em Belém-PA. PPGA/UFPE, 2006

RoOSEVELT, Ana. Arqueologia Amazônica. In. Cunha, M. C. (org.) História dos Índios do Brasil. São Paulo: Companhia das Letras, 1992.

SALLES.V. Cachaça, pena e maracá, Brasil açucareiro, Rio de Janeiro, 27(74):46-55, agos.1969

SANTOS ,E.C.M. Religião e espetáculo: Analise da dimensão espetacular das festas públicas do candomblé. Tese de pós graduação, USP, São Paulo, 2005

SANTOS, E.C.I. Sítios do Brejo- Analise da Cultura material Ceramica . Relatorio de pesquisas do programa institucional de bolsas de iniciação cientifica- PIBIC. Porto Velho, Universidade Federal de Rondonia,2013

SCHAAN, D. P. Cultura Marajoara. Rio de Janeiro: Senac Nacional, 2009 .400p. Edição trilíngue: português /espanhol/inglês. Inclui Bibliografia publicado em parceria com Ed. Senac, São Paulo e Fecomércio/PA.

SCHAAN. D.P. A linguagem Iconográfica da Cerâmica Marajoara.1996.232f. 
Dissertação de Mestrado apresentada ao Programa em História pela Pontifícia Universidade Católica do Rio Grande do Sul. Disponível em < Livros01.livrosgratis.com.br > Acessado em Ago. de 2016.

SCHAAN, D. P. A Representação Humana na Arte Marajoara. Texto escrito para a exposição Marajó: Retratos de Barro. Belém: Museu de Arte de Belém, 1999

SHAAN, D.P. Estatuetas Marajoara: o simbolismo de identidades de gênero em uma sociedade complexa Amazônica. Boletim do Museu Paraense Emilio Goeldi. Séries Antropologia, v.17.n,2, p.23-63,2001b.

SHAAN, D.P. Uma janela para a história pré - colonial da Amazonia: olhando além- e apesar da fases e tradições. Boletim do Museu Paraense Emilio Goeldi, Belém, v.2, n.1,p77-89,2007

SHAAN, D.P; ALVES. D.T: Um ponto, muitas historias: AArqueologia em Santarém. Belém. Gráfica Supercores, 2015

SILVA, Aracy Lopes da. Mitos e cosmologia indígenas no Brasil: breve introdução. In: GRUPIONI, Luis Donisete Benzi (org.) Índios no Brasil. Brasília, Min. da Educação e do Desporto, 1994.

SILVA, Aracy Lopes da e FARIAS, Agenor T.P. Pintura corporal e sociedade: os “partidos”xerente. In: VIDAL, Lux org.). Grafismo indígena: Estudos de Antropologia estética. São Paulo, Fapesp,1992.

SILVA, S. B. Etnoarqueologia dos grafismos Kaingáng: um modelo para a compreensão das sociedades Proto-Jê Meridionais. 2001. 366 p. Tese (Doutorado em Antropologia Social) - Faculdade de São Paulo, São Paulo.

SILVEIRA,E.S. da \& JUNIOR, M. R. de M. A dimensão teórica dos estudos da religião. horizontes históricos, epistemológico e metodológico nas ciências da religião. São Paulo,fonte editorial, 2017.

STRAUSS, Claude Levi. O Feiticeiro e Sua Magia. Publicado sob o título: Le Sorcier et as magie, in Les Tem os Modern es, $4^{\circ}$ ano, $n^{\circ} 41,1949$, pp.3-24 Em Portugues no Antropologia Estrutural. Rio de Janeiro. Tempo Brasileiro,1975, pp.193-213]

STRAUSS, Claude Levi. O pensamento Selvagem [tradução de Tania Pellegrini]Campinas ,SP:Papirus, 1989

VIDAL, L. Grafismo indígena: estudo de antropologia estética. São Paulo: Studio Nobel; FAPESP, Editora da Universidade de São Paulo, 1992.

VIDAL. L. Morte e vida de uma sociedade indígena brasileira: os kayapó- Xikrin do Rio Katete, São Paulo. Hucitec.1977 